\title{
Factors affecting flocculation performance of synthetic polymer for turbidity control
}

\author{
Minyoung Kim*, Seounghee Kim, Jinoh Kim, Sukwon Kang, Sangbong Lee \\ Department of Agricultural Engineering, National Academy of Agricultural Science, Rural Development Administration (RDA), \\ Suwon, Republic of Korea; ${ }^{*}$ Corresponding Author: mykim75@,korea.kr
}

Received 6 October 2012; revised 18 November 2012; accepted 6 December 2012

\section{ABSTRACT}

A multilateral effort into managing nonpoint source pollution from agriculture has gotten much attention for many years. Particularly during the heavy rain season, run-off of turbid water from sloped farmlands, fallow ground and/or unmanaged uplands is deteriorated. Flocculant polymer, commonly used in wastewater treatment facilities, but now exploited to improve control of sediment turbidity by promoting flocculation of particles in construction site. This study used the flocculant polymer to control the discharge of agricultural nonpoint source pollution and fosed on the understanding of how soil-water and polymer properties affect flocculation performce. Therefore, a series of flocculation experi- nts under different conditions was evaluated for better polymer clarification efficiency. Various factors such as flocculant dose, end-over-end inversion of a cylinder, and soil-water properties $(\mathrm{pH}, \mathrm{NaCl}$, organic matter) were studied. The effective flocculant dose that fulfilled fast settling rate was $10 \mathrm{mg} \cdot \mathrm{L}^{-1}$. Additional findings included that 1) increasing $\mathrm{pH}$ decreased the settling rate of soil particle; 2 ) a positive relationship between the percentage of turbidity reduction and a level of salinity in Kaolin suspension was observed, and 3) organic matter in soil solution inhibited PAM adsorption onto soil particles, which caused the reduction of flocculation performance. The findings of this study revealed that flocculant polymer possess good results as a turbidity reducetion measure and could further provide valuable information to make better decision on establishment of Best Management Practice for handling agricultural nonpoint source pollution.

Keywords: Agricultural Nonpoint Source Pollution; Flocculation; Synthetic Polymer; Turbidity Control;

\section{Soil-Water Properties}

\section{INTRODUCTION}

The extent of the impact of climate change on humanity and the environment is not completely studied, but, massive efforts have been made. There are many potential areas affected by global climate change, for examples, human health, biodiversity, food production, economic growth, and water resources. As global climate changes, the changing magnitudes of nonpoint source (NPS) pollution and the effectiveness of best management practices (BMPs) become magnified and uncertain. A term of "nonpoint source pollution" simply means everything including diffuse, difficult to identify, or intermittent source of pollutants [1]. According to the report by Ministry of Environment (2006), the contributing rate of nonpoint source pollution to total loading for the four major rivers ranges from 42 to $69 \%$ depending upon the river basin characteristics [2]. It is well known that agricultural areas are the most problematic and even a small number of storms are usually responsible for the annual load and besides the meteorological factors are highly variable [3].

Control of agricultural pollution usually begins with measurements to control erosion and sediment runoff. Therefore, many BMPs such as grassed waterways, sediment basins, strip cropping, and terracing, were developed and applied in the field. However, the conventional erosion and sediment control measures did not meet the water quality standard. Consequently, one emerging practice promoting flocculation of particles in runoffs using Polyacrylamide (PAM) was introduced. Polyacrylamide is the most common type of polymeric flocculant and its variable functionality, positive, neutral, or negative charge, produces a good settling performance for relative low cost. Polyacrylamide is a white, odorless, and water-soluble polymer with the ability to control surface sealing and crusting; increase seedling emergence, reduce runoff and erosion, as well as reduce fertilizer and pesticide losses. All these benefits alleviate on- and off- 
site pollutions [4].

The process of flocculation is caused by addition of a minute quantity of chemicals termed as flocculants. Most flocculants in use today are synthetic water soluble polymers based on acrylamide and its derivatives and which may include either anionic or cationic groups. The flocculants can be inorganic (aluminum, iron, etc.) or organic (polyacrylamide, starch, etc.) in nature. Previous studied found that a small amount of polymeric flocculants resulted in the same or at least similar results when using inorganic flocculants with large volumes [5]. Flocculation has been used to treat wastewater in sewage and industrial treatment plants for many years, but recently it has been applied to storm water runoff to settle down the solids in runoff.

There is a wide range of flocculants available varying in chemistry, ionic charge, molecular weight, branching, and physical form. Therefore, the selection of a flocculant for particular application is not based upon their chemical and physical composition. Instead, performance parameters (e.g., settling rate, residual turbidity, sediment volume of flocculant consumption) are used to characterize the quality or extent of flocculation achieved with a given flocculant [6]. Understanding the interaction between soil solution and PAM flocculant is important for optimizing flocculant performance. Therefore, this study conducted a series of flocculation experiments under various parameters of soil solution (a change of $\mathrm{pH}, \mathrm{NaCl}$, and organic matter) to determine their effects on settling rate in turbid soil waters.

\section{MATERIALS AND METHODS}

\subsection{Synthetic Polymer and Kaolin Source Clay}

An anionic synthetic polymer, Magnafloc 336 (Ciba Specialty Chemicals, Korea, now BASF Global) with a high molecular weight $\left(10-15\right.$ million $\left.\mathrm{g} \cdot \mathrm{mol}^{-1}\right)$ was used in this study. Its physio-chemical properties are as followings: white granular powder, particle size: $98 \%<$ $1000 \mu \mathrm{m}$, bulk density: $0.8 \mathrm{~g} \cdot \mathrm{cm}^{-3}, \mathrm{pH}$ of $1 \%$ solution at $25^{\circ} \mathrm{C}: 5.5$, viscosity at $25^{\circ} \mathrm{C}$ of $0.5 \%$ solution at shear rate 5.11: $50 \mathrm{cp}$, relative viscosity at $25^{\circ} \mathrm{C}: 4.1$ ). We conducted a series of preliminary study to determine an optimal concentration of PAM, and the results showed that the best settling efficiency of PAM was achieved at a concentration of $10 \mathrm{mg} \cdot \mathrm{L}^{-1}$. This predetermined PAM concentration was fixed as other factors $(\mathrm{pH}$, organic matter and soil-water $\mathrm{NaCl}$ ) were changed to determine their effects on flocculation performance. The standard PAM stock solution was prepared in 1-Liter of deionized (DI) water by adding $10 \mathrm{mg}$ of magnafloc 336 product.

In this study, Kaolin as the dominant clay mineral $(70 \%-90 \%)$ was purchased from the Source Clay Min- erals Repository (Columbia, MO, USA) and used. The components of Kaolin are: $\mathrm{SiO}_{2}$ of $44.2 \%, \mathrm{Al}_{2} \mathrm{O}_{3}$ of $39.7 \%, \mathrm{TiO}_{2}$ of $1.39 \%, \mathrm{Fe}_{2} \mathrm{O}_{3}$ of $0.13 \%, \mathrm{FeO}$ of $0.08 \%$, $\mathrm{MnO}$ of $0.002 \%, \mathrm{MgO}$ of $0.03 \%, \mathrm{Na}_{2} \mathrm{O}$ of $0.013 \%, \mathrm{~K}_{2} \mathrm{O}$ of $0.05 \%$, F of $0.013 \%$ and $\mathrm{P}_{2} \mathrm{O}_{5}$ of $0.034 \%$ (wt/wt), respectively. Its chemical characteristics are followings: $\mathrm{pH}$ between $5 \sim 6$, specific surface area of $10.05 \mathrm{~m}^{2} \cdot \mathrm{g}^{-1}$, cation-exchange capacity (CEC) of $2.0 \mathrm{~mol} \cdot \mathrm{kg}^{-1}$. Kaolin suspensions were prepared immediately before each set of experiments, through mixing accurate weight of clay powder $(75 \mathrm{~g})$ with certain volume of DI water and PAM.

The adjustment of $\mathrm{pH}$ was made by adding hydrochloric acid and sodium hydroxide $(0.1 \mathrm{M} \mathrm{NaOH}$ or $\mathrm{HCl})$ ranging from 4 to 9 . In case of changing a level of soilwater salinity, sodium chloride $(\mathrm{NaCl})$ was added with concentrations of $0.5,1.0,3.0,5.0$ and $10.0 \mathrm{mg} \cdot \mathrm{L}^{-1}$. Humic acid (CAS Number 1415-93-6, Sigma-Aldrich, USA), the major organic constituents of soil, was added to make solutions with concentrations of $0.05,0.1,0.15,0.2$ and $0.25 \mathrm{~g} \cdot \mathrm{L}^{-1}$. Any significant interaction among the treatments was defined with respect to their effect on the flocculation efficiency in this study.

\subsection{Procedure of Flocculation Test}

Each stopped-Plexiglas cylinder was filled with 1 Liter of PAM solution mixed with Kaolin clay powder. After 6-hr of pre-soaking time, a cylinder was closed, inverted 10 times then, set upright. The height of the solid phase was measured at regular time intervals $(0.5,1,3,6,10$, 15, $20 \mathrm{~min})$. The pre-determined pre-soaking time and inversion number were used.

The settling rate was calculated by plotting the curve of height against time (the rate of fall of the mud line in suspension within a measuring cylinder). The sample for turbidity measurement was withdrawn after $20 \mathrm{~min}$ from the previous inverted cylinder using automatic pipette from a half height of below the surface of suspension. The turbidity of these samples was measured using 2100P turbidimeter (HACH Co., USA) calibrated using standard solutions. The samples that withdrawn directly after inverting represent the initial turbidity, and the measured samples after $20 \mathrm{~min}$ are the residual turbidity. The percentage of turbidity removal was calculated using the initial and final readings of turbidity using an equation: ( $\%$ of initial reading of turbidity $-\%$ of final reading of turbidity $) /(\%$ of initial reading of turbidity $) \times 100$.

\subsection{Data Analysis}

Each experiment was conducted in three replicates. Significant differences were analyzed through analysis of variance (ANOVA), where differences were considered significant at 0.05 confidence level. In addition, Pearson correlation coefficients were calculated using Excel to de- 
termine relationships between soil-water properties $(\mathrm{pH}$, soil organic matter, and soil-water $\mathrm{NaCl}$ concentration) and turbidity reduction.

\section{RESULTS AND DISCUSSION}

Settling rate, which was measured from the rate of descent of the mud line, provides a qualitative indication of the aggregate dimensions. It is normally measured by cylinder tests, where dilute polymer is dosed into a standard cylinder mixed by inversion (Figure 1).

\subsection{Preliminary Study on PAM Pre-Soaking Time, Number of End-over-End Inversion and PAM Optimal Dose}

There are many types (powder, liquid, emulsion and block) of PAMs which have slightly different properties and ability to react with a specific solution. Therefore, prior to the flocculation test, we conducted a series of preliminary study to predetermine the essential factors such as PAM pre-soaking time, number of end-over-end cylinder inversion, and PAM optimal dose.

An interesting result found during a preliminary study was that the settling rate varied as a function of the presoaking time. Therefore, this study allowed a various pre-soaking time $(1,3,6,9,12,18$ and $24 \mathrm{hrs})$ prior to an actual flocculation test. The settling velocity was calculated by dividing settling rate with time for clear comparison between each treatment. Flocculation behavior of soil aggregates followed by PAM adsorption onto soil particles requires a certain time to react and the best settling rate of soil particles was achieved at the pre-soaking time of $6 \mathrm{hr}$ (Figure 2). We also found that longer than 6 hrs of pre-soaking time did not improve the flocculation performance.

The effect of the number of end-over-end inversions of the cylinder using the predetermined optimum flocculant dosage $\left(10 \mathrm{mg} \cdot \mathrm{L}^{-1}\right)$ on both the settling rate and the percentage turbidity removal was studied. The settling rate was slightly affected by the number of inversion. It was concluded that the efficient mixing of the flocculant and the suspension in the cylinder requires about 10 inversions (data not shown). We also found that the adding more inversion broke up the aggregates which resulted in higher residual turbidities.

As shown in Figure 3, the settling of Kaolin suspension using PAM became faster as the amount of PAM increased. It can be explained by the fact that PAM was adsorbed on clay particles (high specific surface area) and helped particles to aggregate into clusters. The comparison study of clay suspension with and without using PAM, it was observed that the height of interface decreased with time at the beginning, and the sedimentation

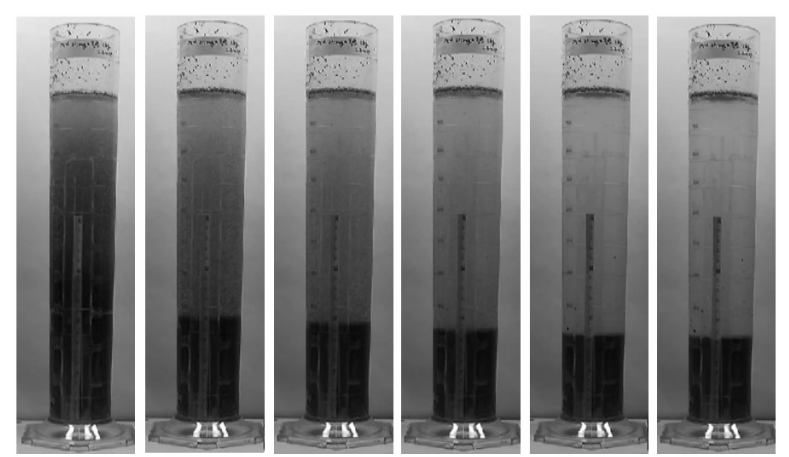

Figure 1. Schematic of flocculation test using 1-L cylinders.

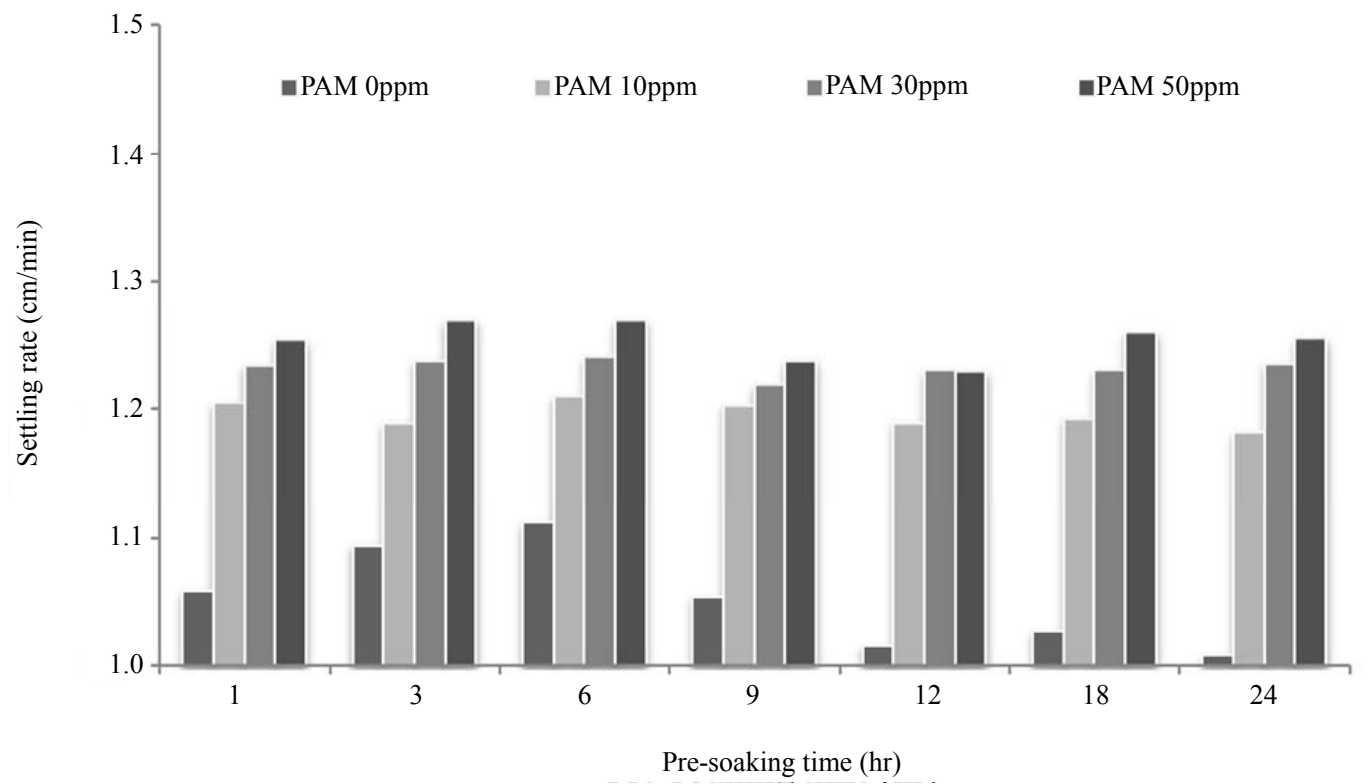

Figure 2. Effect of pre-soaking time on flocculation performance. 


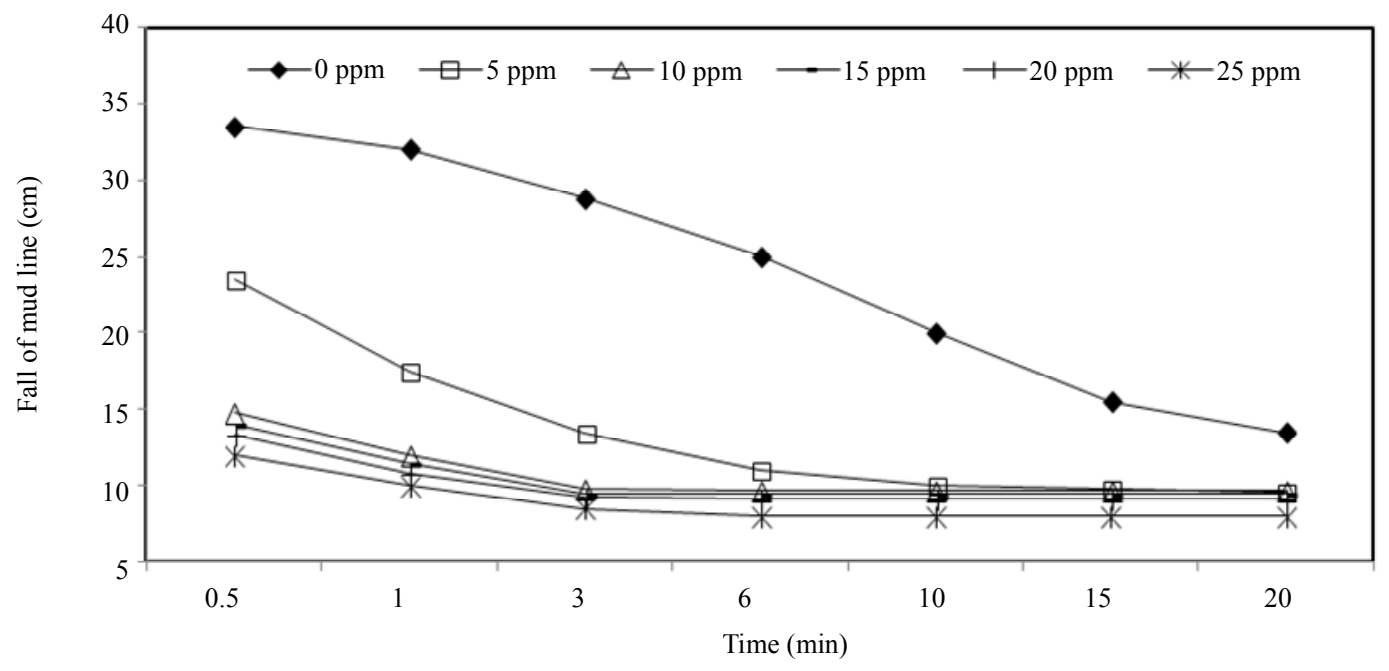

Figure 3. Determination of optimal dose of PAM in Kaolin solution.

became lower for both cases as settling time increased. When settling occurs using PAM, a sharp decrease in settling rate was noticed. Also the beginning settling period was very short using PAM compared with its counterpart without PAM. Moreover increase in PAM dose from 10 to $25 \mathrm{mg}$ showed an appreciable increase in settling rate but has a little effect on the percentage removal of clay turbidity. It is interesting to note that the faster settling rates and lower residual turbidities may be achieved by using $10 \mathrm{mg}$ of PAM.

\subsection{Effect of Suspension pH}

The ranges of $\mathrm{pH}$ values from 4 to 9 covered the three basics (acidic, alkaline, and neutral) at given predetermined pre-soaking time $(6 \mathrm{hr})$, end-over-end inversion number (10 times), and optimal PAM dose $\left(10 \mathrm{mg} \cdot \mathrm{L}^{-1}\right)$. The results showed that anionic PAM was slightly effecttive in neutral $(\mathrm{pH}=7.0)$ or acid solutions $(\mathrm{pH}=4 \sim 6)$ rather than alkaline solution $(\mathrm{pH}=8 \sim 9)$ (Figure 4). Overall the percentage of turbidity removal for acidic and neutral $\mathrm{pHs}$ was about $74 \%$, while the one for alkaline pHs was about $60 \%$. This can be explained by the fact that kaolinite forms a card-house-type structure due to the electrostatic attraction between the negatively charged basal surface and the positively charged edge surface at low $\mathrm{pH}$. In case of high $\mathrm{pH}$, both kaolinite basal and edge surface are negatively charged and therefore the electrostatic repulsion exists, which indicates low rate of flocculation capacity [7].

The overall trend of settling rates as a function of $\mathrm{pH}$ values was consistent with a study by Taylor et al. (2002) [8]. However, it was not significantly different $(p>0.05)$ as expected. This might be caused by the fact that a large increase in the residual turbidity after longer time (10 $\min$ vs. $60 \mathrm{~min}$ ) allowed for flocs to settle [8]. This indi- cates that only 20 min settling time may not be enough to get any noticeable result.

\subsection{Effect of Suspension $\mathrm{NaCl}$}

We used deionized water in all tests. Therefore, any available cations were from the soil itself. Sodium chloride added for varying the conditions. A level of salts in Kaolin suspension was prepared by adding Sodium chloride $(\mathrm{NaCl})$ acted as a monovalent cation source. Figure 5 shows that the interaction of anionic PAM by the same minerals and soils increased significantly as the concentrations of dissolved salts increased. The percentage of turbidity removal was ranged from $48 \%$ to $58 \%$ as the concentration of $\mathrm{NaCl}$ increased. In addition, the correlation between turbidity reading of supernatant and $\mathrm{NaCl}$ concentration was highly negative $(r=-0.914)$ at a confidence level of $95 \%$.

Since the concept of relative flocculation power is a comprehensive index of charge screening ability for cations, this phenomenon signified that the mechanism of PAM sorption enhancement by salts is mainly because of their charge screening ability [9]. In this study, addition of monovalent cation, namely, $\mathrm{Na}^{+}$showed a slight synergistic effect of about $10 \%$ on flocculating activity throughhout the $\mathrm{NaCl}$ range $\left(0.1 \sim 10 \mathrm{mg} \cdot \mathrm{L}^{-1}\right)$.

\subsection{Effect of Suspension Organic Matter}

Organic matter had a negative effect on PAM flocculation performance as shown in Figure 6. It is obvious that the sorptive affinity of the soils to PAM increased after some of the organic matter was removed. This phenomenon was in agreement with earlier observations by Nadler and Letey (1989) [10].

Soil organic matter plays an important role in forming 

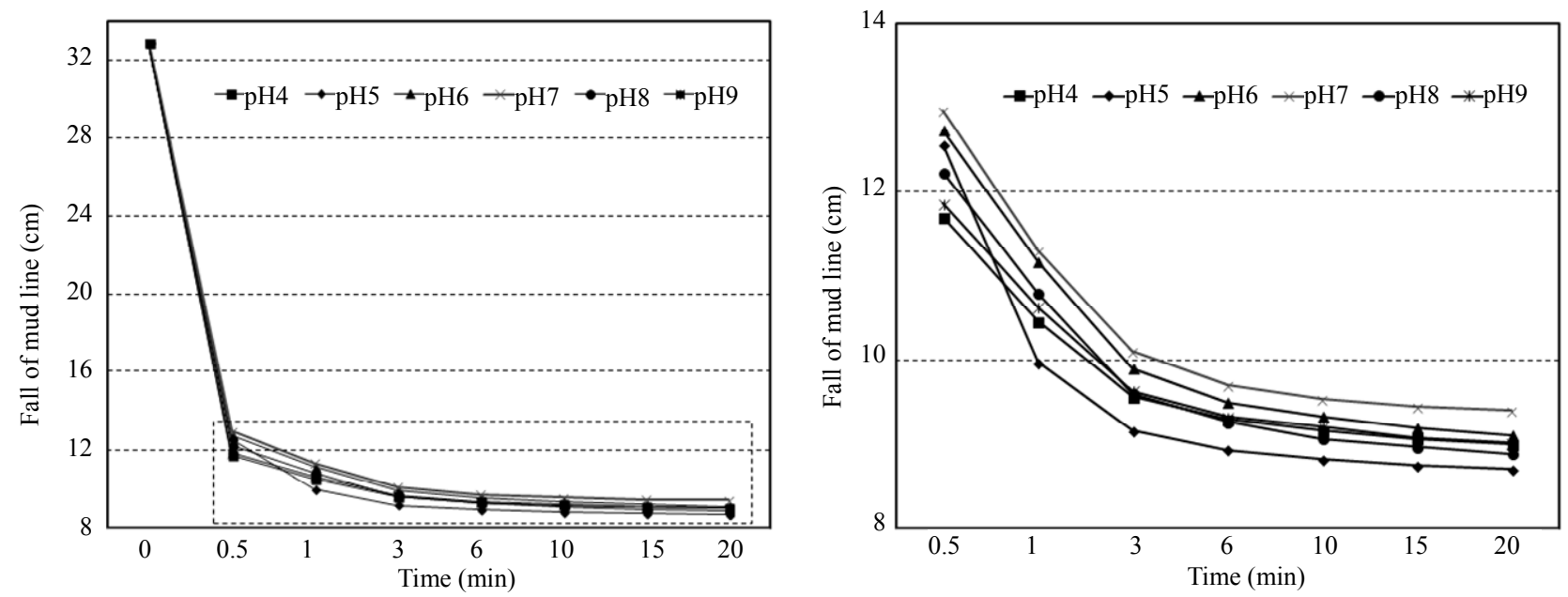

Figure 4. Effect of $\mathrm{pH}$ on settling rate. (Left) entire view, (Right) enlarged of dot area of entire view.
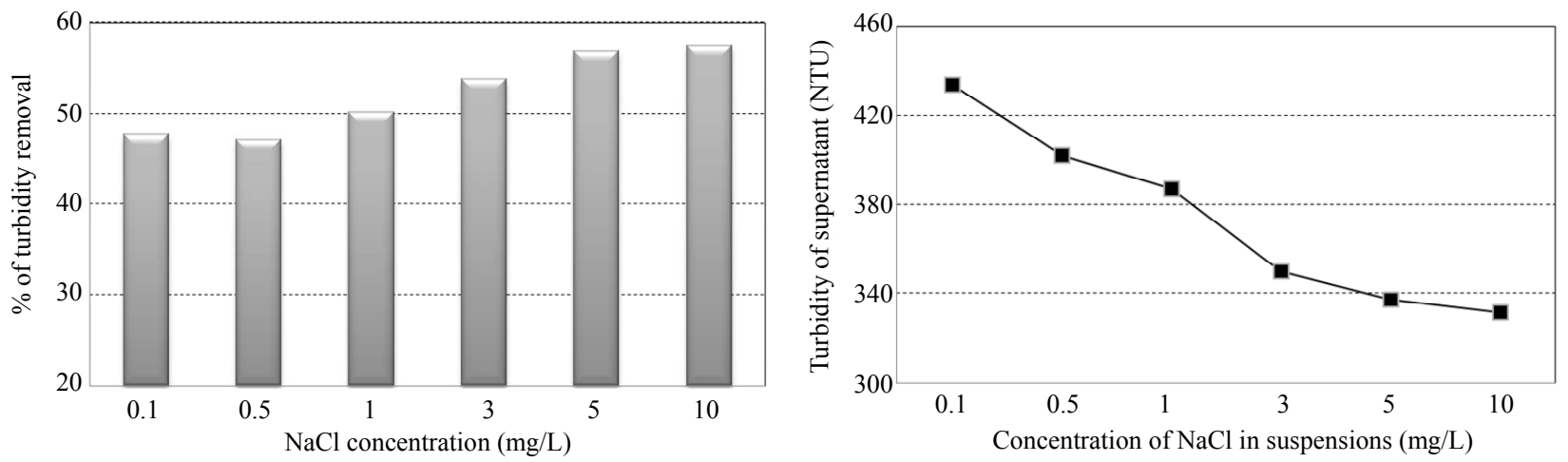

Figure 5. Effect of soil-water salt level on flocculation performance (Left). Changes of turbidity in supernatant at different concentration of $\mathrm{NaCl}$ in suspensions (Right).
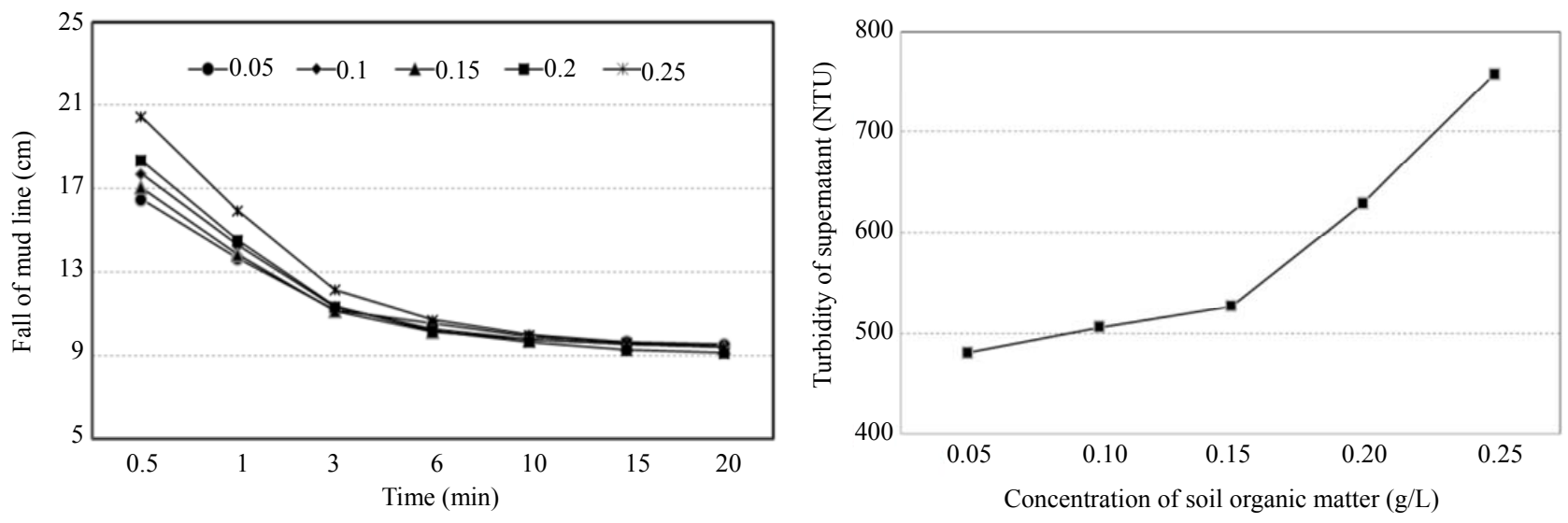

Figure 6. Response of flocculation performance with a change of organic matter (Left), response of turbidity in supernatant on a change of organic matter (Right).

soil aggregates. However, at a presence of flocculant, removal of soil organic matter breaks down soil aggregates and exposes new accessible sites for PAM sorption, which definitely increases the sorption amount of PAM. In addition, in the normal soil $\mathrm{pH}$ range of 5 to 9 , the majority of functional groups in organic matter carry a ne- gative charge. Decrease in the content of organic matter reduced the electrostatic repulsion between soil particles and anionic PAM molecules, and thus increased the flocculation performance. The correlation between turbidity readings of supernatant and concentration of soil organic matter was highly positive $(r=0.968)$. 


\section{CONCLUSIONS}

The flocculation kinetics of anionic polyacrylamide in Kaolin suspensions has been investigated as a function of $\mathrm{pH}(4 \sim 9)$, soil-water $\mathrm{NaCl}\left(0.5 \sim 10 \mathrm{mg} \cdot \mathrm{L}^{-1}\right)$ and soil organic matter $\left(0.05 \sim 0.25 \mathrm{~g} \cdot \mathrm{L}^{-1}\right)$. Essential factors, such as PAM \& soil-water pre-soaking time, the number of end-over-end inversion and PAM optimal dosage, were pre-determined through a preliminary study and they were fixed throughout the a series of flocculation test.

The settling rate of Kaolin suspension without PAM was low especially and the settling rate and percentage turbidity removal increased with increasing PAM dose. The optimum PAM dose required for obtaining a faster settling rate and corresponding clear supernatants was $10 \mathrm{mg}$. Settling rate and percentage of turbidity removal slightly decreased as the number of end-over-end inversions of the cylinder increased. The effect of $\mathrm{pH}$ showed that the flocculation performance decreased as $\mathrm{pH}$ increased due to electrostatic repulsion as the majority of soil surfaces are negatively charged. The presence of monovalent cation $\left(\mathrm{Na}^{+}\right)$in Kaolin solution increased PAM sorption and finally lead to more soil particles flocculated. High organic matter contents reduced the PAM sorption, possibly because of the reduction of accessible sorptive sites once organic matter can cement inorganic soil components into soil aggregates and increase the electrostatic repulsion between soil particle surfaces and PAM molecules.

This research explored the effect of soil and water properties on PAM flocculation using a series of cylinder test. The kinetics of PAM flocculation under the field conditions might be different; however, the findings of this study clearly showed that synthetic polymer (PAM) had great capacity of turbidity reduction. Results from this study could provide valuable information to make better decision on establishment of Best Management Practice in agriculture to meet water quality standards.

\section{ACKNOWLEDGEMENTS}

This study was carried out with the support of "Research Program for Agricultural Science \& Technology Development (Project No. 907097032012)", National Academy of Agricultural Science, Rural De- velopment Administration, Republic of Korea.

\section{REFERENCES}

[1] Novotny, P.E. and Chesters, G.C. (1981) Handbook of nonpoint pollution: Sources and management. Van Nostrand Reinhold Co., New York.

[2] Korea Ministry of Environment (2006) Guidance manual to control nonpoint source pollution. Korea Ministry of Environment, Gwacheon.

[3] Rhee, H., Yoon, C., Lee, S. and Choi, Y. (2012) Analysis of nonpoint source pollution runoff from urban land uses in South Korea. Environmental Engineering Research, 17, 47-56. doi:10.4491/eer.2012.17.1.047

[4] Green, V.S. and Stott, D.E. (2001) Polyacrylamide: A review of the use, effectiveness, and cost of a soil erosion control amendment. Proceeding of the 10th International Soil Conservation Organization Meeting, West Lafayette, 24-29 May 2001, 384-389

[5] Akers, R.J. and Werd, A. (1977) Coagulation and flocculation. Solid-Liquid Separation Technology, New York.

[6] Rigo, L.N., Pinto, A.M., Denardin, N.D. and Schneider, I.A.H. (2002) Flocculatoin of fine fluorite particles with Corynebacterium xerosis and commercial long chain polymers. Brazilian Journal of Microbiology, 33, 331- 332. doi:10.1590/S1517-83822002000400010

[7] Laylor, M.L., Morris, G.E., Self, P.G. and Smart, R.C. (2002) Kinetics of Adsorption of high molecular weight anionic polyacrylamide onto Kaolinite: The flocculation process. Journal of Colloid and Interface Science, 250, 28-36. doi:10.1006/jcis.2002.8341

[8] Latif, M.A., Eldin, M.S. and Kady, M. F. (2005) Settling of high concentrations of clay suspended in water by nonionic polyacrylamide flocculants. Alexandria Engineering Journal, 44, 325-338.

[9] Lu, J.H., Wu, L. and Letey, J. (2002) Effects of soil and water properties on anionic polyacrylamide sorption. Soil Science Society of America Journal, 66, 578-584. doi:10.2136/sssaj2002.0578

[10] Nadler, A. and Letey, J. (1989) Adsorption isotherms of polyanions on soils using tritium labeled compounds. Soil Science Society of America Journal, 53, 1375-1378. doi:10.2136/sssaj1989.03615995005300050012x 